\title{
Evidence of concurrent and prospective associations between early maltreatment and ADHD through childhood and adolescence
}

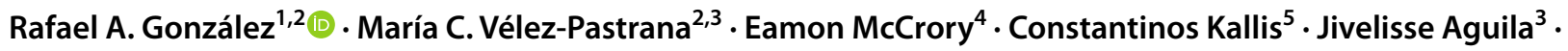 \\ Glorisa Canino ${ }^{6} \cdot$ Hector Bird $^{7}$
}

Received: 19 July 2018 / Accepted: 17 January 2019 / Published online: 22 March 2019

(c) The Author(s) 2019

\begin{abstract}
Purpose An emerging body of work suggests a link between childhood maltreatment and attention-deficit hyperactivity disorder (ADHD). However, research examining the role of maltreatment in the early course of the disorder lacks robust evidence from longitudinal studies. Our aim was to examine concurrent and prospective associations between maltreatment experiences and ADHD diagnosis and sex differences, and to estimate the association between repetitive maltreatment exposure and ADHD through childhood and adolescence.

Methods Data were obtained from the Boricua Youth Study, a longitudinal study of 2480 children and adolescents of Puerto Rican background. Neglect, physical, emotional and sexual abuse, and foster placement were regressed on ADHD diagnosis measured at each of three waves using the Diagnostic Interview Schedule for Children-IV. Multilevel regressions estimated the effects of exposure on ADHD, adjusted by age, sex, income, household education, parental psychopathology, comorbidity and ADHD medication status.

Results Emotional abuse and foster placement had robust associations with ADHD diagnosis. For girls, physical abuse had a threefold increase in the odds of having ADHD diagnosis; for boys, associations were observed only for emotional abuse. Prospective models examining the risk of ADHD following maltreatment provided initial evidence for the effects of physical abuse on ADHD, and a linear trend for repetitive exposure suggested increased probability for disorder persistence.

Conclusions Associations between early maltreatment and ADHD were robust. Different categories of maltreatment increase the likelihood of ADHD for girls and boys. Increased exposure to maltreatment may predict symptom persistence. Interventions addressing ADHD must consider the effects of both sex and family environment.
\end{abstract}

Keywords Maltreatment $\cdot$ ADHD $\cdot$ Emotional abuse $\cdot$ Physical abuse $\cdot$ Trauma

Electronic supplementary material The online version of this article (https://doi.org/10.1007/s00127-019-01659-0) contains supplementary material, which is available to authorized users.

Rafael A. González

r.gonzalez@imperial.ac.uk

1 Centre for Mental Health, Division of Brain Sciences, Department of Medicine, Imperial College London, 7th floor Commonwealth Building, Du Cane Road, London W12 0NN, UK

2 Center for Evaluation and Sociomedical Research, Graduate School of Public Health, University of Puerto Rico, San Juan, PR, USA

3 Ph.D. Program in Clinical Psychology, Carlos Albizu University, San Juan, PR, USA
4 Division of Psychology and Language Sciences, University College London, London, UK

5 Institute of Translational Medicine, University of Liverpool, Liverpool, UK

6 Behavioral Sciences Research Institute, University of Puerto Rico School of Medicine, San Juan, PR, USA

7 Columbia University, New York, NY, USA 


\section{Introduction}

Childhood maltreatment, including physical and sexual abuse and neglect, is a common risk factor associated with long-term psychiatric morbidity and mortality. In 2014 alone, 6.6 million children in the USA were involved in referrals for alleged maltreatment [1], including 702,000 victims of child abuse and neglect and 1580 fatalities. Psychiatric morbidity attributed to early maltreatment is extensive, including associations with mood [2], personality [3] and substance use disorders [4]. Children exposed to repetitive traumatic events are also at risk for developing anxiety disorders and PTSD [5]. There is also an emerging body of work linking experiences of childhood maltreatment with attention deficit/hyperactivity disorder (ADHD) [6-9].

ADHD is a disorder with childhood onset ( $<12$ years), characterized by dimensions of both hyperactivity/impulsivity and inattentiveness. ADHD is a highly heritable disorder relative to other forms of psychiatric morbidity [10]. It is also one of the most prevalent psychiatric disorders in children and adolescents, ranging from 2 to $7.1 \%$, based on global meta-analytic rates $[11,12]$. Whilst the importance of the role of parenting and family factors in the development of mental health problems is widely accepted, there remains a lack of clarity regarding the role of early trauma and abuse in the early progression of ADHD. Several lines of evidence point to a potential link between maltreatment and ADHD.

First, studies examining the relationship between ADHD, maltreatment and childhood adversity have reported significant associations with physical abuse [6, $7,13,14]$, sexual abuse [7, 15-17] and with neglect [15]. For instance, Ouyang et al. [15] reported that ADHD was associated with neglect and sexual abuse in a sample of 14,322 participants in the National Longitudinal Study of Adolescent Health. Another large-scale study reported associations with physical abuse, albeit with a combined category including ADHD coexisting with conduct and oppositional defiant disorders (CD/ODD) [14]. Smaller cross-sectional studies have also reported associations between both physical and sexual abuse and ADHD [16, 18]. Furthermore, adolescents who had experienced parental divorce, marital disruption and physical abuse combined had an increase likelihood of ADHD diagnosis by 15 times, compared to non-abused adolescents [6].

More recent population-based studies indicate a more robust association. A study of 23,000 Canadian men and women reported that about $41 \%$ of those who were physically maltreated were more likely to have clinical symptoms of ADHD [7]. Additionally, researchers using population-based Swedish registers analysed data from 18,168 adult twins (20-46 years), comparing ratings of a general category of child maltreatment and self-reported ADHD symptoms. Their twin study design allowed to account for family-level confounding, and reported that child maltreatment including physical and sexual abuse, neglect and witnessing family violence significantly predicted ADHD symptoms in adulthood [9].

Lack of associations between early maltreatment and ADHD have also been reported [19, 20]. Recently, researchers using the Environmental-Risk study data [21] reported associations between a combined category comprising various forms of abuse with neglect in childhood through young adulthood [22]. However, after accounting for environmental and genetic confounding, associations with abuse/neglect remained, but were concentrated only amongst those with comorbid CD. This suggested an adverse environmental role in behavioural aspects rather than in actual ADHD symptoms. Inconsistent findings may be explained by several limitations in the existing evidence base. The majority of these studies have adopted cross-sectional designs [6, 8, 20], used screening tools to assess ADHD rather than clinical diagnosis $[7-9,15]$ and conflated ADHD with other disruptive disorders, such as $\mathrm{CD}[14,18,23,24]$, precluding the ability to isolate the direct effects of maltreatment on ADHD. Moreover, these have often failed to account for common confounding factors, such as comorbidity and parental psychopathology [24, 25].

Second, early trauma is known to be associated with alterations in cognitive processes implicated in ADHD, including dysfunctional biases in the allocation of attention [26], deficits in reward processing and in executive function [27]. Disruption in the ability to self-regulate is thought to be a central mechanism in the pathway between early maltreatment and persistent psychiatric symptoms [28]. This is consistent with anatomical and functional alterations in brain regions (e.g. anterior cingulate and dorsolateral pre-frontal cortexes) identified in individuals exposed to trauma [29], and also in individuals with ADHD [30]. In addition, posttraumatic stress disorder (PTSD) that may occur in response to intense traumatic experiences is prevalent amongst victims of child abuse [5] and is also comorbid with ADHD [31]. For example, a study of Iraqi children whose parents have PTSD shows overlapping ADHD and PTSD symptoms, which the authors argue may not reflect true comorbidity [32]. PTSD symptoms of hyperarousal and cognitive impairment amongst maltreated children may overlap with, or confound the inattention, hyperactivity and emotional symptoms of ADHD [31].

Some important sex differences have been reported across existing studies. Childhood sexual and physical abuse were robustly associated with an increased likelihood of reporting a diagnosis of ADHD [7]. Nevertheless, for women but not men, exposure to parental domestic violence was also 
independently associated with ADHD. Girls with ADHD also presented with significantly higher scores for emotional and sexual abuse than those without ADHD [17]. It is generally understood that the symptom profile and trajectory of ADHD differs by sex [33], as well as the vulnerability to various types of maltreatment events [34]. For instance, girls were reportedly more susceptible and exhibited more severe ADHD symptoms than boys when exposed to both domestic violence and victimisation [35]. Differential psychiatric correlates by sex have been reported for children in care, with boys having higher rates of ADHD, but girls being more prone to also developing PTSD [36]. Sex differences have been also observed in functional connectivity and inhibitory control upon exposure to child maltreatment [37]. Examining the potential impact of sex on the relationship between early maltreatment and ADHD through longitudinal studies may help elucidate the differential mechanisms for males and females that may be relevant for intervention.

Therefore, despite an existing body of work investigating the association between childhood maltreatment and ADHD, robust evidence from longitudinal studies during childhood and adolescence is limited. In the present study we sought to address the limitations of previous studies. Specifically, we used a unique three-wave longitudinal design, with participants fully characterized by a formal clinical diagnosis. Furthermore, we were able to investigate the impact of maltreatment exclusively on ADHD, with sufficient power to stratify analyses by sex, ensuring that relevant family-level factors, timing of maltreatment experience, psychiatric comorbidity and medication status were taken into account.

Our guiding hypothesis for this study is that childhood maltreatment experiences and adversity (including physical, emotional, sexual abuse, neglect and being taken to foster care) will be significantly associated with ADHD diagnosis after accounting for contextual and comorbidity factors. We aimed to address four main questions. First, are childhood maltreatment and adversity experiences directly associated with ADHD diagnosis, generally and/or stratified by sex? Second, do family-level and/or psychiatric covariates explain any associations found? Third, is there evidence of a prospective link between maltreatment and ADHD? Finally, is there evidence of a linear trend between exposure to maltreatment events and ADHD persistence across waves?

\section{Methods}

\section{Participants and procedures}

The sample was drawn from the Boricua Youth Study (BYS), the full details of which have been described elsewhere [38]. In brief, 2491 Latino male and female children ages 5-13 years and their caretakers were interviewed at two sites, the South Bronx in New York city $(n=1138)$ and in the standard metropolitan areas (SMA) of Puerto Rico $(n=1353)$. Both samples were multi-stage probability community samples, weighted to represent their target populations. Data were collected in three annual waves between 2000 and 2004, mostly spanning a 3 -year period (2001-2004).

An eligible household had to include a child age 5-13 years and a parent/caretaker at baseline, both selfidentifying as of Puerto Rican background. Child/adult interviews were conducted simultaneously but separately by two interviewers, at participants' homes, using computerized versions of instruments. The IRB of the New York State Psychiatric Institute and the University of Puerto Rico School of Medicine approved all procedures; informed consent was obtained.

For this study, we selected all of the youth from the original study who had completed at least one of the assessments (both youth and caretaker) on ADHD at any of the three waves (Table 1). This represented a total of 2480 young persons. The interviews at the first wave (baseline, T1) took place when participants were aged between 5 and 13 years; the last follow-up (T3) was at ages 7 through 15 years. The follow-up interviews occurred annually for two consecutive years.

\section{Measures}

The measures were culturally validated for Puerto Rican children and families. Specifically, the Diagnostic Interview Schedule for Children-IV is available in both English and Spanish. The remainder of the questionnaires were translated from English to Spanish, back-translated, and culturally adapted following a model that considers the semantic, content, technical, criterion and conceptual equivalence of cross-language versions of an instrument to ensure that they were equivalent to the original [39].

\section{Maltreatment}

\section{Neglect, physical abuse and emotional abuse}

The Parental Discipline Practices Scale [40] was used to collect data on these three types of abuse. For the purpose of the present research, we only used children's report. This includes eight items in a four-point scale that asks about parent use of each of six forms of non-physical discipline and two forms of physical punishment. Alphas for nonphysical discipline and physical punishment and abuse range from 0.70 to $0.76[38,40]$. 
Table 1 Description of the adolescent sample across (3) waves in the Boricua Youth Study

\begin{tabular}{|c|c|c|c|c|}
\hline & Wave 1 & Wave 2 & Wave 3 & All \\
\hline Covariates & $2480(36.3)$ & $2267(32.5)$ & $2176(31.2)$ & $6923(100.0)$ \\
\hline \multicolumn{5}{|l|}{ Site } \\
\hline NYC & $1,129(84.2)$ & $1,001(83.5)$ & 964 (83.6) & $3,094(83.8)$ \\
\hline PR & $1351(15.8)$ & $1266(16.5)$ & $1212(16.4)$ & $3829(16.2)$ \\
\hline \multicolumn{5}{|l|}{ Sex } \\
\hline Male & $1279(50.9)$ & $1161(50.5)$ & $1125(51.2)$ & $3565(50.9)$ \\
\hline Female & $1201(49.1)$ & $1106(49.5)$ & $1051(48.8)$ & 3358 (49.1) \\
\hline \multicolumn{5}{|l|}{ Household Ed } \\
\hline$<$ High school & $514(27.9)$ & 461 (27.6) & $451(28.3)$ & $1426(27.9)$ \\
\hline High school & 1154 (50.9) & 1064 (51.6) & 1009 (50.6) & 3227 (51.0) \\
\hline$>$ High school & 803 (21.2) & 733 (20.8) & 709 (21.2) & 2245 (21.1) \\
\hline \multicolumn{5}{|l|}{ Income band } \\
\hline I & $861(33.8)$ & $818(36.3)$ & 741 (36.4) & $2,420(35.4)$ \\
\hline II & $846(32.3)$ & $786(33.3)$ & 783 (32.6) & $2,415(32.7)$ \\
\hline III & $472(22.1)$ & $383(18.3)$ & $360(17.6)$ & 1,215 (19.5) \\
\hline IV & $301(11.9)$ & $279(12.1)$ & $292(13.5)$ & $872(12.4)$ \\
\hline Parental psychopathology (any) & 933 (34.9) & $846(33.8)$ & $826(35.0)$ & $2,605(34.6)$ \\
\hline ADHD & $196(7.5)$ & $140(6.9)$ & $117(5.6)$ & $453(6.7)$ \\
\hline ADHD medication & $96(4.3)$ & $99(5.3)$ & $96(5.1)$ & $291(4.9)$ \\
\hline PTSD (subthreshold) & $53(2.0)$ & $27(1.0)$ & $30(1.5)$ & $110(1.5)$ \\
\hline $\mathrm{CD}$ & $22(0.9)$ & $15(0.8)$ & $12(0.9)$ & $49(0.8)$ \\
\hline \multicolumn{5}{|l|}{ Maltreatment/adversity } \\
\hline Emotional & $376(19.3)$ & $219(12.2)$ & $169(10.2)$ & $764(14.1)$ \\
\hline Physical & $390(17.9)$ & $190(11.1)$ & $112(6.6)$ & $692(12.1)$ \\
\hline Neglect & $268(11.0)$ & $109(5.1)$ & $75(3.2)$ & $452(6.6)$ \\
\hline Sexual & $113(5.0)$ & $46(2.9)$ & $24(1.4)$ & $183(3.2)$ \\
\hline Foster placement & $66(2.4)$ & $58(2.2)$ & $56(2.2)$ & $180(2.3)$ \\
\hline
\end{tabular}

All weighted estimates and proportions

$N Y C$ New York city, $P R$ Puerto Rico, $A D H D$ attention deficit/hyperactivity disorder, $C D$ conduct disorder, $P T S D$ post-traumatic stress disorder

\section{Sexual abuse}

The sexual victimization measure from Finkelhor and Dziuba-Leatherman [41] was used to collect data about sexual abuse. This includes six screener queries about sexual abuse/ assault that are answered yes/no. Sexual incidents defined as completed include serious noncontact incidents (perpetrator touching a child in a sexual way, but without contact to private parts) and contact incidents. These data were collected from children's report, as indicated in [41].

Ever been in foster placement was one of the very few variables in the study that was not measured across waves.

\section{Attention deficit/hyperactivity disorder (ADHD)}

A diagnosis of ADHD in the child was established using the parent/caretaker's report on the Diagnostic Interview Schedule for Children IV (DISC-IV) [42], on each wave. Diagnosis was determined when symptom criteria and one
DISC-IV diagnosis-specific impairment and age of onset criteria were met.

We examined whether children and adolescents in our sample who consistently reported maltreatment across waves had an increased likelihood of persisting with an ADHD diagnosis by the end point of the study (i.e. linear trend). To address this, groups of persistent ADHD and in remission were created on the basis of the frequency of positive diagnosis on each wave. Specifically, children were classified as "persistent" if they had more than one positive ADHD classification and their diagnostic status at the end point (T3) was positive. Those classified "in remission" had only one positive classification and did not meet ADHD criteria at the end point (T3). Children without diagnosis on the three waves were classified as non-ADHD cases. Children with diagnosis only at the end point (T3) were excluded for this section of the analyses $(n=32)$, as there was no way to assess whether they would persist based on only one assessment. 


\section{Demographic characteristics and covariates}

Data on demographic characteristics including child age and sex, and indicators of family socioeconomic status and parental education (parent's highest academic grade) were collected. The DISC-IV was also used to establish PTSD and $\mathrm{CD}$ diagnostic categories on each wave. The rates of depression and anxiety disorders were very low at T1, therefore not included as covariates. Parental psychopathology was assessed via the Family History Screen for Epidemiologic Studies (FHE) that screens for 15 DSM-based diagnoses, including depression and mood, anxiety disorders, substance misuse and antisocial personality traits [43].

The BYS used the following question to assess medication use for ADHD in the past year: "Taken any medication in past year for being overactive or trouble paying attention?". A follow-up question queried the specific name of the medication and these were used to classify those who were taking medication in the past year.

\section{Analytical strategy}

All maltreatment categories (except foster placement) and ADHD were assessed on each wave. Therefore, all logistic regression models were multilevel, accounting for the dependence of data collected longitudinally by modeling the repeated measurement within the same individual as random effects. To estimate the effects of exposures on ADHD over the entire study period regardless of time point, we included time as a covariate on all models. The logistic regression mixed models therefore provided a single odds ratio (OR) estimate (as the measure of effect size), confidence intervals (CI) and significance values of the relationship between early maltreatment and ADHD over the course of the study.

ADHD diagnosis was regressed on each of the maltreatment categories individually. Study site (New York, San Juan) was included as a design covariate on all models to account for potential differences. Analyses examining the effects of early maltreatment and foster placement were then adjusted for age, sex, income, household education, any parental psychopathology and whether youths had received medication for ADHD (time varying). To examine their independent contribution to ADHD, all significant types of maltreatment/foster placement were also modeled simultaneously. All maltreatment $\times$ sex and maltreatment $\times$ wave interactions were fitted on adjusted models.

To estimate the extent to which any association between early maltreatment and family adversity is accounted for by comorbidity, models for ADHD regressed on significant exposures were fitted including PTSD and CD as covariates.

To investigate a prospective association between maltreatment types and ADHD, we fitted models using time-lagged $(T-1)$ measures of all maltreatment variables following the previously described steps for including covariates and confounders. These models do not include observations for ADHD diagnosis on T1 (i.e. time lagged). Lastly, we regressed the ADHD persistence groups (no ADHD, in remission, persistent $\mathrm{ADHD}$ ) on a variable, combining any exposure to maltreatment on each time point, with a range of $0-3$. We used ordered logit regressions after establishing the proportionality of odds based on likelihood ratio test $(p>0.05)$.

Our weighted analyses adjust for differences in the probability of selection, correct standard errors and match the sample to the 2000 Census in terms of age and sex distributions. All analyses were performed using Stata 14.

\section{Results}

A total of 2480 children and adolescents were interviewed on the first wave of the BYS (Table 1). Of these, there were $1279(50.9 \%)$ males and 1201 (49.1\%) females. Out of the whole sample, 2176 participants completed the third wave for a retention rate of $88 \%$. Further demographic characteristics of this sample have been published elsewhere [38].

\section{Concurrent associations between early maltreatment, foster placement and ADHD}

Emotional abuse, physical abuse and foster placement were significantly associated with ADHD diagnosis across waves (Table 2). Physical abuse was not associated with ADHD after accounting for covariates. Emotional abuse and foster placement remained significant with robust associations after adjustments were made for all demographics, any parental psychopathology and ADHD medication. The estimates for emotional abuse $[2.46(1.49,4.07), p=0.001]$ and foster placement [5.47 $(2.01,14.92), p=0.001]$ remained significant after adjusting for all maltreatment simultaneously.

We found evidence of effect modification after examining interactions by sex on the association of physical abuse with ADHD diagnosis, with increased likelihood for girls [2.77 $(1.13,6.82), p=0.03]$.

\section{Differential associations by sex}

The weighted prevalence of ADHD on wave 1 for boys was $10.2 \%$ and for girls $4.8 \%$. Amongst boys, only emotional abuse was related to ADHD across waves, albeit with large effect sizes (Table 2). In girls, ADHD was associated with physical abuse with a threefold increase in the odds. There was a trend for an association with emotional abuse amongst girls $(p<0.10)$, but this did not reach statistical significance. 
Table 2 Association between early maltreatment and foster placement with ADHD diagnosis through adolescence

\begin{tabular}{|c|c|c|c|c|c|c|}
\hline \multirow[t]{2}{*}{ Exposures } & \multicolumn{2}{|l|}{ ADHD } & \multicolumn{2}{|l|}{ Baseline model $^{\mathrm{a}}$} & \multicolumn{2}{|c|}{ Family, MHD, medication $^{\mathrm{b}}$} \\
\hline & No $(\%)$ & Yes $(\%)$ & OR (95\% CI) & $p$ value & OR (95\% CI) & $p$ value \\
\hline \multicolumn{7}{|l|}{ All youth } \\
\hline Emotional & 13.5 & 23.9 & $2.52(1.50,4.51)$ & $<0.001$ & $2.41(1.45,4.03)$ & 0.001 \\
\hline Physical & 11.5 & 20.8 & $1.71(1.01,2.89)$ & 0.04 & $1.50(0.93,2.42)$ & $0.10 \dagger$ \\
\hline Neglect & 6.4 & 10.1 & $1.49(0.78,2.86)$ & 0.23 & $1.37(0.77,2.45)$ & 0.29 \\
\hline Sexual & 3.2 & 3.6 & $1.07(0.33,3.50)$ & 0.91 & $1.10(0.36,3.35)$ & 0.87 \\
\hline Foster placement & 2.1 & 5.0 & $4.81(1.93,11.98)$ & 0.001 & $5.11(1.96,13.36)$ & 0.001 \\
\hline Boys & 89.8 & 10.2 & & & & \\
\hline Emotional & 14.1 & 23.9 & $2.69(1.48,4.88)$ & 0.001 & $2.59(1.41,4.76)$ & 0.002 \\
\hline Physical & 14.9 & 19.4 & $1.16(0.59,2.30)$ & 0.66 & $1.11(0.61,2.03)$ & 0.73 \\
\hline Neglect & 6.9 & 9.9 & $1.17(0.48,2.89)$ & 0.73 & $1.14(0.51,2.58)$ & 0.75 \\
\hline Sexual & 3.3 & 2.9 & $0.89(0.21,3.81)$ & 0.88 & $0.86(0.22,3.28)$ & 0.82 \\
\hline Girls & 95.2 & 4.8 & & & & \\
\hline Emotional & 12.8 & 24.0 & $2.16(0.96,4.85)$ & 0.06 & $2.08(0.91,4.74)$ & 0.08 \\
\hline Physical & 8.2 & 24.5 & $3.22(1.63,6.36)$ & 0.001 & $3.01(1.47,6.18)$ & 0.003 \\
\hline Neglect & 5.9 & 10.4 & $2.07(0.73,5.84)$ & 0.17 & $2.08(0.74,5.86)$ & 0.16 \\
\hline Sexual & 3.0 & 5.5 & $1.44(0.39,5.35)$ & 0.59 & $1.49(0.40,5.49)$ & 0.55 \\
\hline
\end{tabular}

All weighted percentages and estimates

$A D H D$ attention deficit/hyperactivity disorder, $O R$ odds ratio, $C I$ confidence interval, $M H D$ mental health disorder

${ }^{\dagger}$ Significant interaction OR 2.77 [1.13, 6.82], $p=0.03$

${ }^{a}$ Models adjusted for study site (New York, Puerto Rico) and wave (time)

${ }^{b}$ Models adjusted for ${ }^{a}$ and age, gender (except for stratified analyses), household education and income band, any parental psychopathology and having taken ADHD medication (time-varying)

\section{Role of comorbidity}

All previously significant multivariate models for the association of maltreatment with ADHD were adjusted for time-varying diagnoses of PTSD and CD (Table 3). The effects of both emotional abuse and foster placement were significant after adjusting for this mental health condition on the sample as a whole, on emotional abuse for males and physical abuse for females.
Table 3 Examining the role of comorbidity on the association between early psychological/ emotional abuse and foster placement with ADHD symptoms through adolescence

\begin{tabular}{|c|c|c|c|c|c|c|}
\hline \multirow[t]{2}{*}{ Exposures } & \multicolumn{2}{|c|}{$\begin{array}{l}\text { Posttraumatic stress } \\
\text { disorder }\end{array}$} & \multicolumn{2}{|l|}{ Conduct disorder } & \multicolumn{2}{|c|}{$\begin{array}{l}\text { Multi-abuse/all comorbid- } \\
\text { ity }\end{array}$} \\
\hline & OR $(95 \%$ CI $)$ & $p$ value & OR $(95 \%$ CI $)$ & $p$ value & OR $(95 \%$ CI $)$ & $p$ value \\
\hline \multicolumn{7}{|l|}{ All youth } \\
\hline Psychological & $2.49(1.47,4.23)$ & 0.001 & $2.55(1.51,4.31)$ & 0.001 & $2.56(1.51,4.33)$ & 0.001 \\
\hline Foster placement & $4.98(1.79,13.52)$ & 0.002 & $3.84(1.40,10.56)$ & 0.009 & $3.87(1.27,11.82)$ & 0.02 \\
\hline \multicolumn{7}{|l|}{ Males } \\
\hline Psychological & $2.74(1.46,5.13)$ & 0.002 & $2.75(1.48,5.10)$ & 0.001 & $2.73(1.46,5.08)$ & 0.002 \\
\hline \multicolumn{7}{|l|}{ Females } \\
\hline Physical & $2.93(1.43,6.00)$ & 0.003 & $2.62(1.33,5.18)$ & 0.006 & $2.62(1.30,5.28)$ & 0.007 \\
\hline
\end{tabular}

All weighted percentages and estimates

$A D H D$ attention deficit/hyperactivity disorder, $O R$ odds ratio, $C I$ confidence interval

${ }^{a}$ Models adjusted for study site (New York, Puerto Rico), wave (time), age, gender (except for stratified analyses), any parental psychopathology and having taken ADHD medication (time-varying)

${ }^{b}$ Models adjusted for ${ }^{a}$ and all comorbid disorders (time-varying) and maltreatment types (time-varying) simultaneously 


\section{Prospective associations between maltreatment and ADHD}

Only physical abuse was significantly associated with ADHD in prospective (i.e. lagged) models of ADHD across waves. This model was initially fitted adjusting for age, sex, income, household education, any parental psychopathology and ADHD medication [OR 2.01 (1.09, 3.71), $p<0.05$ ]. Then it was also adjusted for all comorbid disorders simultaneously [OR 2.05 (1.10, 3.81), $p<0.05$ ].

\section{Increased maltreatment exposure and ADHD persistence}

To examine the presence of a linear trend from increased exposure to maltreatment across waves, we regressed ADHD diagnostic status (no ADHD, in remission, persistent ADHD) on the number of maltreatment exposures (range 0-3). The proportional odds assumption was met for this analysis, providing confidence in interpreting results from ordinal model outcomes. We found that for each additional wave with a physical or emotional abuse event, the odds of having ADHD, and of having persistent ADHD symptoms, significantly increased by $40 \%$ [OR $1.40(1.08,1.81)$, $p=0.01]$. The model-predicted probabilities for groups of "in remission" and "persistent ADHD" are displayed in Supplemental Fig. 1.

\section{Discussion}

This longitudinal study examined the relationship between early maltreatment and ADHD, addressing the following questions: whether maltreatment and adverse experiences are directly associated with ADHD diagnosis in general and according to sex; whether the reported associations are explained by family and psychiatric covariates; if there is a prospective link between maltreatment and ADHD; and, if there is a linear trend between increased exposure to maltreatment and ADHD persistence across time. Our results show maltreatment and adverse experiences including emotional abuse, physical abuse and foster placement were significantly associated with ADHD diagnosis. Across the total sample, emotional abuse and having been in foster placement had robust associations with ADHD diagnosis across waves. Subgroup analyses by sex revealed that for girls, physical abuse had a threefold increase in the odds of having ADHD diagnosis. Amongst boys, associations were observed only for emotional abuse. The associations between maltreatment experiences and ADHD were not accounted for by demographic and family-level factors, parental psychopathology, psychiatric comorbidity or time-dependent ADHD medication status. Prospective models examining the risk of ADHD following maltreatment provided some evidence for an effect of physical abuse on ADHD, with a linear trend between exposure to maltreatment and increased probability for ADHD diagnosis and its persistence.

\section{Associations with maltreatment: emotional and physical abuse}

The association between emotional abuse and ADHD is a novel finding at the population level. Very few studies have reported associations of ADHD with emotional abuse. These associations were robust for the total sample, but particularly amongst boys. The measure used specifically captures negative evaluations from their parents, demeaning attitudes and perceived threat, which is consistent with recent findings in which parents' negative expressed emotion about their children predicted a persistent ADHD trajectory [44]. Nevertheless, findings on parental expressed emotion and hostility in relation with ADHD are mixed, with reports of negative findings [45]; others have found that children's ADHD may precede [46] or evoke [47] parental hostility. Parents of children with ADHD report high levels of parenting-related stress [16], which in turn may contribute to maltreatment of their children.

The majority of prior studies have focused on physical abuse $[6,7,18,20]$, whilst our total sample estimates for physical abuse were marginal and better explained by covariates. Nevertheless, sex-stratified analyses show strong associations between physical abuse and ADHD for girls, consistent with previous studies [7, 20]. Our findings did not show associations for neglect or for sexual abuse, contrasting with other reports [7, 15, 16, 48]. Discrepancies between our findings and those of previous studies might be explained by the use of ADHD self-rating symptom scales across previous studies [7, 15, 23]. In addition, our study used reports of maltreatment obtained directly from interviews with children, as opposed to parent-reported maltreatment, or official records. Studies addressing maltreatment tend to overestimate the impact of each type of abuse on psychiatric symptoms by not taking their correlation into consideration, thereby not fitting all these exposures simultaneously [14].

We also found evidence of a prospective link between maltreatment and ADHD, as well as a linear trend between maltreatment and ADHD persistence. Because ADHD was assessed at each consecutive year, our results from mixed models indicate that maltreatment may be linked with persistence of ADHD diagnosis. Further, our linear trend results lend support to the role of increased abuse exposure on ADHD symptom persistence. Reports of physical abuse preceded diagnosis in prospective models, suggesting abuse may have operated as a risk factor for exacerbating ADHD. 
This effect from cross-lagged models was not observed for other forms of maltreatment or adversity. Further studies are necessary to better understand the neural mechanisms that correlate with ADHD symptoms following exposure to abuse, and any causative role from child maltreatment, as has been recently suggested [9].

\section{Potential mechanisms explaining ADHD- maltreatment associations}

One plausible mechanism for the prospective relation between maltreatment and ADHD considers the potential influence of parental or caretaker's behaviour on the course of symptoms. Self-regulation is a key component of ADHD, as part of the executive dysfunction that characterizes the disorder [49, 50], and maladaptive parenting and abuse can disrupt the child's ability to regulate themselves [51]. Disruptions in self-regulation may be at the core of the link between early maltreatment and psychiatric symptoms [26, 27]. Parental behaviour may also interact with early symptom onset and in turn reinforce problem behaviours in children, via poor supervision, reactiveness and inconsistent rule setting. Further, both parental behaviours [52] and physical abuse [53] have been shown to moderate genetic vulnerability for ADHD. Meanwhile, low maternal warmth [54] and frequent parental criticism [44] have been recently related with a worse ADHD symptom trajectory.

Evidence to date suggests that the relationship between ADHD and childhood maltreatment may be bi-directional; maltreatment and neglect may have a possible etiologic and exacerbating role in ADHD, but persistent problem behaviours in children with ADHD may also increase the risk of maltreatment for them. Our most robust findings using all data indicated longitudinal associations between emotional abuse and ADHD, based on mixed models. Because these observations were taken within a very narrow period of three consecutive years, it is likely that these results captured reciprocal effects between maltreatment and ADHD symptoms, and may be better understood in the context of research on bidirectional influences. Studies examining bi-directional influences to date have focused on callous, unemotional traits $[55,56]$ and conduct problems $[56,57]$ in children, and emerging personality disorder in adolescents [58]. Nonetheless, methodological issues have been raised recently in study of boys reporting lack of effects between parenting and children's externalizing behaviours [59]. Discrepancy in findings may reflect differences in methods used to estimate these complex directional relationships, such as cross-lagged models [56, 59] or generalized estimating equations [57]. Further research examining cross-lagged associations that focuses specifically on ADHD through childhood is warranted.

\section{Sex differences}

We found differential associations between physical and emotional abuse with ADHD for girls and boys, respectively. Studies have generally reported associations in either gender and provide evidence for family influences in expressions of inattention exclusively in girls [25]. Our finding of significant interaction by sex in terms of levels of physical abuse indicates that associations with ADHD vary significantly by sex. This was evident on our stratified analyses, which is consistent with research highlighting different mechanisms and vulnerabilities underlying associations between maltreatment exposure and neurodevelopmental disorders by sex [26]. A recent study found significant gene $\times$ environment $(\mathrm{G} \times \mathrm{E})$ interactions between dopamine transporter (DAT1) genotype and a general measure of maltreatment including physical abuse predicting severe ADHD, but only in girls [60]. Future studies should elucidate pathways on the effects of early maltreatment by sex, which would have implications for targeted evaluation and intervention. On this evidence, blanket treatment recommendations targeting boys and girls indiscriminately are unlikely to be effective. Future research should also examine potential differences in the longer-term patterns of comorbidity between boys and girls with ADHD who are exposed to early abuse (e.g. antisocial behaviours, self-harm).

\section{Children in foster placement, ADHD and the role of attachment}

We found robust associations between foster placement with ADHD diagnosis. The prevalence of ADHD among children who have been removed from their biological parent's home was twice as large as that among children who have not been removed. This is consistent with studies that show children in foster care frequently present symptoms of ADHD and other externalizing disorders [13]. These children may be more difficult to care for, and more vulnerable to being maltreated, which may lead to being taken into care. But it is also conceivable that the experience of being removed from home and placed in foster care will be sufficiently stressful for the child to exhibit symptoms that may be related or resemble ADHD (e.g. hypervigilance), which can be independent of any maltreatment or adverse experiences preceding the foster placement. Whilst there are studies relating reasons for placement with specific symptoms, or to specific diagnostic groups [61], very few 
studies have addressed the possible traumatic impact of the removal experience itself. Indeed, we found the effect of foster placement to be independent of the effect of different types of maltreatments that were studied, as models adjusting for the different types of maltreatment show an independent contribution of foster placement to ADHD. Also, there was no association between specific type of maltreatment and removal from home in our study, which may be related to the youths' and authorities' discrepant perceptions of maltreatment and abuse. Discrepancies related to reasons for removal of a child from home have been found amongst professionals in agencies involved in child welfare [62]. Meanwhile, the child's perspective on the necessity for removal is seldom considered [63]. Nonetheless, conduct disorder (CD) explained a sizeable portion of the variance in models for foster placement, an indication of a potentially non-random process in which those most challenging children were taken into foster care in our sample.

Children in care often present with early-disrupted attachments. In attachment theory, young children establish bonds with their caregivers as a survival instinct, pursuing safety from their mothers during times of stress [64]. Its disruption is associated with clinical presentations of uncontrolled emotional displays and patterns of behaviour and developmental difficulties [65], including cognitive and symptoms typically observed amongst young persons with social communication difficulties, inattention and impulsivity [65, 66]. For instance, evidence from the English and Romanian Adoptees (ERA) study [67], in which children were exposed to extreme early deprived environments, shows they often presented with an ADHD-like syndrome or would meet criteria for ADHD, with some having received stimulant medication treatment [66]. Research shows overlap between attachment disorders and ADHD, with a likely increase in the risk for each other [65]. The most recent findings from the ERA study showed that young adults who had experienced a high level of early deprivation were over seven times more likely to meet criteria for an ADHD-like disorder, persisting into adulthood. Their results also suggest enduring alterations to brain structure and function [68]. The potential presence of issues of attachment in the children of our sample should be considered in examining the present results, as this was not directly measured in the study's original design.

\section{Family environment and genetic influences}

Family-level and psychiatric covariates, including parental psychopathology, psychiatric comorbidity and ADHD medication status, did not explain the observed associations between maltreatment and ADHD. Nevertheless, it is plausible that parents who have difficulties with impulse control associated with ADHD symptoms are likely to engage in harsh parenting practices - that may exacerbate their children's disruptive behaviours - whilst also passing on genes that may render their offspring more vulnerable for developing ADHD. This refers to gene-environment correlation $\left(\mathrm{GE}_{\mathrm{r}}\right)$. Thus, we attempted to account for a portion of the rGE by adjusting our models for the presence of any parental psychiatric morbidity. However, this needs to be directly addressed in future research in this area. Evidence suggests the interplay between environment and candidate genes may explain variance in ADHD outcome, with maltreatment leading to the development of ADHD symptoms through interactions with MAOA [53] and DAT2 [60]. Interactions between exposure to abuse and candidate genes are well established for $\mathrm{CD}$ and other disruptive disorders, but remain understudied in ADHD.

\section{Limitations}

The present findings should be interpreted in light of several limitations. First, although we accounted in our models for combining datasets from two sites based on a similar ethnic group, some unexplained variance might be present in estimates. Second, it remains unclear whether these findings may be fully generalizable to children from other ethnic groups beyond Puerto Ricans. Third, the criteria for ADHD diagnosis were based on DSM-IV. This is a sample with a high prevalence of ADHD, and transforming algorithms, such as modifying age of onset criterion, would have likely increased this rate and we opted to be conservative. Also, we did not use alternative (e.g. teacher) reports as part of the assessment of ADHD, which is a necessary criterion for clinical diagnosis (i.e. pervasiveness). Nevertheless, recent findings from a study by experts in the field reported that parental and teacher reports of symptoms do not differ statistically and produce comparable diagnostic accuracy [69]. Fourth, maltreatment was self-reported by children, and this approach entails the limitations inherent to self-reportrecall bias is unaccounted for and may have been a factor in measures of abuse. However, the study used a well-validated instrument used in MECA studies, and we believe this is an improvement over more common approaches that are based on parent's reports.

ADHD is well known for its comorbidity with most psychiatric disorders. The decision to focus on $\mathrm{CD}$ and on PTSD in the present research was twofold. Firstly, because early trauma and maltreatment are risk factors for $\mathrm{CD}$, and especially PTSD, these were selected as covariates of interest when examining that ADHD may have an independent association with the same family- environment exposures. Secondly, the prevalence for other psychiatric covariates 
such as anxiety disorders, depression, psychosis and substance use disorders was very low in this sample, especially on wave 1 . There would not have been sufficient power to detect statistical differences for these other comorbidities.

\section{Conclusions}

Children who are exposed to maltreatment and adversity, particularly emotional abuse and children placed in foster care, have increased likelihood of ADHD. Different types of maltreatments increase the likelihood of ADHD for girls and boys. Specifically, physical abuse seems more closely associated with ADHD in girls, in contrast to emotional abuse in boys. Finally, increased exposure to maltreatment across time raised the probability that ADHD symptoms would persist. The findings point to the importance of identifying families at risk for maltreatment and/or clarifying any abuse history in the family, and may indicate a potential protective role of early intervention and parent training for an adverse trajectory of ADHD. In addition, child-protective service agencies should seek to reduce the negative impact of foster placement on children's mental health and risk of ADHD. Moreover, our findings provide further support for the view that sex differences are relevant to the etiology, course and development of ADHD and require further attention by clinicians during assessment, formulation and intervention.

Acknowledgements The Boricua Youth Study has been supported by the National Institutes of Health Grant MH56401 (H. Bird). The research efforts of Rafael A. González, María C. Vélez-Pastrana and Jivelisse Aguila were partly supported the National Institute on Drug Abuse Grant 5R24DA024868-05 (C. Albizu). The authors acknowledge the contribution of all of the dedicated staff who participated in this study.

\section{Compliance with ethical standards}

Conflict of interest The authors declare no conflict of interest.

Open Access This article is distributed under the terms of the Creative Commons Attribution 4.0 International License (http://creativeco mmons.org/licenses/by/4.0/), which permits unrestricted use, distribution, and reproduction in any medium, provided you give appropriate credit to the original author(s) and the source, provide a link to the Creative Commons license, and indicate if changes were made.

\section{References}

1. U.S. Department of Health \& Human Services (2016) Child Maltreatment 2014. In: U.S. Department of Health \& Human Services AfCaF, Administration on Children, Youth and Families, Children's Bureau. http://www.acf.hhs.gov/programs/cb/research-data. Accessed 25 Oct 2016
2. Branje SJT, van Doorn MD, van der Valk IE, Meeus WHJ (2009) Parent-adolescent conflict, conflict resolution, and adolescent adjustment. J Appl Dev Psychol 30:195-204

3. Johnson JG, Cohen P, Brown J, Smailes EM, Bernstein DP (1999) Childhood maltreatment increases risk for personality disorders during early adulthood. Arch Gen Psychiatry 56(7):600-606

4. Puetz VB, McCrory E (2015) Exploring the relationship between childhood maltreatment and addiction: a review of the neurocognitive evidence. Curr Addict Rep 2(4):318-325. https://doi. org/10.1007/s40429-015-0073-8

5. Walker JL, Carey PD, Mohr N, Stein DJ, Seedat S (2004) Gender differences in the prevalence of childhood sexual abuse and in the development of pediatric PTSD. Arch Women Ment Health 7(2):111-121. https://doi.org/10.1007/s00737-003-0039-z

6. Cohen AJ, Adler N, Kaplan SJ, Pelcovitz D, Mandel FS (2002) Interactional effects of marital status and physical abuse on adolescent psychopathology. Child Abuse Neglect 26(3):277-288

7. Fuller-Thomson E, Lewis DA (2015) The relationship between early adversities and attention-deficit/hyperactivity disorder. Child Abuse Negl 47:94-101. https://doi.org/10.1016/j.chiab u.2015.03.005

8. Guendelman MD, Owens EB, Galan C, Gard A, Hinshaw SP (2015) Early-adult correlates of maltreatment in girls with attention-deficit/hyperactivity disorder: increased risk for internalizing symptoms and suicidality. Dev Psychopathol 28:1-14

9. Capusan AJ, Kuja-Halkola R, Bendtsen P, Viding E, McCrory E, Marteinsdottir I, Larsson H (2016) Childhood maltreatment and attention deficit hyperactivity disorder symptoms in adults: a large twin study. Psychol Med 46(12):2637-2646. https://doi. org/10.1017/S0033291716001021

10. Thapar A, O'Donovan M, Owen MJ (2005) The genetics of attention deficit hyperactivity disorder. Hum Mol Genet $14 \mathrm{Spec}$ No. 2:R275-R282. https://doi.org/10.1093/hmg/ddi263

11. Willcutt EG (2012) The prevalence of DSM-IV attention-deficit/ hyperactivity disorder: a meta-analytic review. Neurotherapeutics 9(3):490-499. https://doi.org/10.1007/s13311-012-0135-8

12. Sayal K, Prasad V, Daley D, Ford T, Coghill D (2018) ADHD in children and young people: prevalence, care pathways, and service provision. Lancet Psychiatry 5(2):175-186. https://doi. org/10.1016/S2215-0366(17)30167-0

13. Linares LO, Li M, Shrout PE, Ramirez-Gaite M, Hope S, Albert A, Castellanos FX (2010) The course of inattention and hyperactivity/impulsivity symptoms after foster placement. Pediatrics 125(3):e489-e498. https://doi.org/10.1542/peds.2009-1285

14. Perales J, Olaya B, Fernandez A, Alonso J, Vilagut G, Forero CG, San L, Alda JA, Haro JM (2013) Association of childhood adversities with the first onset of mental disorders in Spain: results from the ESEMeD project. Soc Psychiatry Psychiatr Epidemiol 48(3):371-384

15. Ouyang L, Fang X, Mercy J, Perou R, Grosse SD (2008) Attention-deficit/hyperactivity disorder symptoms and child maltreatment: a population-based study. J Pediatr 153(6):851-856

16. Briscoe-Smith AM, Hinshaw SP (2006) Linkages between child abuse and attention-deficit/hyperactivity disorder in girls: behavioral and social correlates. Child Abuse Neg1 30(11):1239-1255. https://doi.org/10.1016/j.chiab u.2006.04.008

17. Rucklidge JJ, Brown DL, Crawford S, Kaplan BJ (2006) Retrospective reports of childhood trauma in adults with ADHD. J Atten Disord 9(4):631-641

18. Ford JD, Racusin R, Ellis CG, Daviss WB et al (2000) Child maltreatment, other trauma exposure, and posttraumatic symptomatology among children with oppositional defiant and attention deficit hyperactivity disorders. Child Maltreat 5(3):205-217

19. Merry SN, Andrews LK (1994) Psychiatric status of sexually abused children 12 months after disclosure of abuse. J Am 
Acad Child Adolesc Psychiatry 33(7):939-944. https://doi. org/10.1097/00004583-199409000-00002

20. Ford JD, Racusin R, Daviss WB, Ellis CG et al (1999) Trauma exposure among children with oppositional defiant disorder and attention deficit-hyperactivity disorder. J Consult Clin Psychol 67(5):776-789

21. Fisher HL, Caspi A, Moffitt TE, Wertz J, Gray R, Newbury J, Ambler A, Zavos H, Danese A, Mill J, Odgers CL, Pariante C, Wong CC, Arseneault L (2015) Measuring adolescents' exposure to victimization: the environmental risk (E-Risk) longitudinal twin study. Dev Psychopathol 27(4 Pt 2):1399-1416. https://doi. org/10.1017/S0954579415000838

22. Stern A, Agnew-Blais J, Danese A, Fisher HL, Jaffee SR, Matthews T, Polanczyk GV, Arseneault L (2018) Associations between abuse/neglect and ADHD from childhood to young adulthood: a prospective nationally-representative twin study. Child Abuse Neg1 81:274-285. https://doi.org/10.1016/j.chiab u.2018.04.025

23. Pelcovitz D, Kaplan SJ, DeRosa RR, Mandel FS, Salzinger S (2000) Psychiatric disorders in adolescents exposed to domestic violence and physical abuse. Am J Orthopsychiatry 70(3):360 369. https://doi.org/10.1037/h0087668

24. Villodas MT, Litrownik AJ, Thompson R, Jones D, Roesch SC, Hussey JM, Block S, English DJ, Dubowitz H (2015) Developmental transitions in presentations of externalizing problems among boys and girls at risk for child maltreatment. Dev Psychopathol 27(1):205-219. https://doi.org/10.1017/S09545794140007 28

25. Becker KB, McCloskey LA (2002) Attention and conduct problems in children exposed to family violence. Am J Orthopsychiatry 72(1):83-91

26. Kelly PA, Viding E, Puetz VB, Palmer AL, Mechelli A, Pingault JB, Samuel S, McCrory EJ (2015) Sex differences in socioemotional functioning, attentional bias, and gray matter volume in maltreated children: a multilevel investigation. Dev Psychopathol 27(4 Pt 2):1591-1609

27. Cicchetti D, Cowell RA, Rogosch FA, Toth SL (2015) Childhood maltreatment and its effect on neurocognitive functioning: timing and chronicity matter. Dev Psychopathol 27(2):521-533

28. Herringa RJ, Birn RM, Ruttle PL, Burghy CA, Stodola DE, Davidson RJ, Essex MJ (2013) Childhood maltreatment is associated with altered fear circuitry and increased internalizing symptoms by late adolescence. Proc Natl Acad Sci USA 110(47):1911919124. https://doi.org/10.1073/pnas.1310766110

29. Teicher MH, Samson JA (2016) Annual research review: enduring neurobiological effects of childhood abuse and neglect. J Child Psychol Psychiatry 57(3):241-266. https://doi.org/10.1111/ jcpp. 12507

30. Hart H, Chantiluke K, Cubillo AI, Smith AB, Simmons A, Brammer MJ, Marquand AF, Rubia K (2014) Pattern classification of response inhibition in ADHD: toward the development of neurobiological markers for ADHD. Hum Brain Mapp 35(7):3083-3094. https://doi.org/10.1002/hbm.22386

31. Spencer AE, Faraone SV, Bogucki OE, Pope AL, Uchida M, Milad MR, Spencer TJ, Woodworth KY, Biederman J (2016) Examining the association between posttraumatic stress disorder and attention-deficit/hyperactivity disorder: a systematic review and meta-analysis. J Clin Psychiatry 77(1):72-83. https://doi. org/10.4088/JCP.14r09479

32. Daud A, Rydelius PA (2009) Comorbidity/overlapping between ADHD and PTSD in relation to IQ among children of traumatized/ non-traumatized parents. J Atten Disord 13(2):188-196. https:// doi.org/10.1177/1087054708326271

33. Nussbaum NL (2012) ADHD and female specific concerns: a review of the literature and clinical implications. J Atten Disord 16(2):87-100. https://doi.org/10.1177/1087054711416909
34. Finkelhor D, Ormrod R, Turner H, Hamby SL (2005) The victimization of children and youth: a comprehensive, national survey. Child Maltreat 10(1):5-25

35. Lewis T, Schwebel DC, Elliott MN, Visser SN, Toomey SL, McLaughlin KA, Cuccaro P, Tortolero Emery S, Banspach SW, Schuster MA (2015) The association between youth violence exposure and attention-deficit/hyperactivity disorder (ADHD) symptoms in a sample of fifth-graders. Am J Orthopsychiatry 85(5):504-513. https://doi.org/10.1037/ort0000081

36. Jackson LJ, O'Brien K, Pecora PJ (2011) Posttraumatic stress disorder among foster care alumni: the role of race, gender, and foster care context. Child Welf 90(5):71-93

37. Elton A, Tripathi SP, Mletzko T, Young J, Cisler JM, James GA, Kilts CD (2014) Childhood maltreatment is associated with a sexdependent functional reorganization of a brain inhibitory control network. Hum Brain Mapp 35(4):1654-1667

38. Bird HR, Davies M, Duarte CS, Shen S, Loeber R, Canino GJ (2006) A study of disruptive behavior disorders in Puerto Rican youth: II. Baseline prevalence, comorbidity, and correlates in two sites. J Am Acad Child Adolesc Psychiatry 45(9):1042-1053

39. Bravo M, Woodbury-Farina M, Canino GJ, Rubio-Stipec M (1993) The Spanish translation and cultural adaptation of the Diagnostic Interview Schedule for Children (DISC) in Puerto Rico. Cult Med Psychiatry 17(3):329-344

40. Goodman SH, Hoven CW, Narrow WE, Cohen P, Fielding B, Alegria M, Leaf PJ, Kandel D, Horwitz SM, Bravo M, Moore R, Dulcan MK (1998) Measurement of risk for mental disorders and competence in a psychiatric epidemiologic community survey: the National Institute of Mental Health Methods for the Epidemiology of Child and Adolescent Mental Disorders (MECA) Study. Soc Psychiatry Psychiatr Epidemiol 33(4):162-173

41. Finkelhor D, Dziuba-Leatherman J (1994) Children as victims of violence: a national survey. Pediatrics 94(4 Pt 1):413-420

42. Shaffer D, Fisher P, Lucas CP, Dulcan MK, Schwab-Stone ME (2000) NIMH Diagnostic Interview Schedule for Children Version IV (NIMH DISC-IV): description, differences from previous versions, and reliability of some common diagnoses. $\mathrm{J}$ Am Acad Child Adolesc Psychiatry 39(1):28-38. https://doi. org/10.1097/00004583-200001000-00014

43. Lish JD, Weissman MM, Adams PB, Hoven CW, Bird H (1995) Family psychiatric screening instruments for epidemiologic studies: pilot testing and validation. Psychiatry Res 57(2):169-180

44. Musser ED, Karalunas SL, Dieckmann N, Peris TS, Nigg JT (2016) Attention-deficit/hyperactivity disorder developmental trajectories related to parental expressed emotion. J Abnorm Psychol 125(2):182-195. https://doi.org/10.1037/abn0000097

45. Richards JS, Vasquez AA, Rommelse NN, Oosterlaan J, Hoekstra PJ, Franke B, Hartman CA, Buitelaar JK (2014) A follow-up study of maternal expressed emotion toward children with attentiondeficit/hyperactivity disorder (ADHD): relation with severity and persistence of ADHD and comorbidity. J Am Acad Child Adolesc Psychiatry 53(3):311-319 e311. https://doi.org/10.1016/j. jaac.2013.11.011

46. Lifford KJ, Harold GT, Thapar A (2009) Parent-child hostility and child ADHD symptoms: a genetically sensitive and longitudinal analysis. J Child Psychol Psychiatry 50(12):1468-1476. https:// doi.org/10.1111/j.1469-7610.2009.02107.x

47. Harold GT, Leve LD, Barrett D, Elam K, Neiderhiser JM, Natsuaki MN, Shaw DS, Reiss D, Thapar A (2013) Biological and rearing mother influences on child ADHD symptoms: revisiting the developmental interface between nature and nurture. J Child Psychol Psychiatry 54(10):1038-1046. https://doi.org/10.1111/ jcpp. 12100

48. Hadianfard H (2014) Child abuse in a group of children with ADHD in comparison with normal children. Int J Commun Based Nurs Midwifery IJCBNM 2(2):77-84 
49. Barkley RA (2001) The executive functions and self-regulation: an evolutionary neuropsychological perspective. Neuropsychol Rev 11(1): $1-29$

50. Velez-Pastrana MC, Gonzalez RA, Rodriguez Cardona J, Purcell Baerga P, Alicea Rodriguez A, Levin FR (2015) Psychometric properties of the Barkley deficits in executive functioning scale: a Spanish-language version in a community sample of Puerto Rican adults. Psychol Assess. https://doi.org/10.1037/pas0000171

51. Cowell RA, Cicchetti D, Rogosch FA, Toth SL (2015) Childhood maltreatment and its effect on neurocognitive functioning: timing and chronicity matter. Dev Psychopathol 27(2):521-533. https:// doi.org/10.1017/S0954579415000139

52. Sonuga-Barke EJ, Oades RD, Psychogiou L, Chen W, Franke B, Buitelaar J, Banaschewski T, Ebstein RP, Gil M, Anney R, Miranda A, Roeyers H, Rothenberger A, Sergeant J, Steinhausen HC, Thompson M, Asherson P, Faraone SV (2009) Dopamine and serotonin transporter genotypes moderate sensitivity to maternal expressed emotion: the case of conduct and emotional problems in attention deficit/hyperactivity disorder. J Child Psychol Psychiatry 50(9):1052-1063. https://doi.org/10.111 $1 / \mathrm{j} .1469-7610.2009 .02095 . x$

53. Kim-Cohen J, Caspi A, Taylor A, Williams B, Newcombe R, Craig IW, Moffitt TE (2006) MAOA, maltreatment, and geneenvironment interaction predicting children's mental health: new evidence and a meta-analysis. Mol Psychiatry 11(10):903-913. https://doi.org/10.1038/sj.mp.4001851

54. Cartwright KL, Bitsakou P, Daley D, Gramzow RH, Psychogiou L, Simonoff E, Thompson MJ, Sonuga-Barke EJ (2011) Disentangling child and family influences on maternal expressed emotion toward children with attention-deficit/hyperactivity disorder. J Am Acad Child Adolesc Psychiatry 50(10):1042-1053. https://doi. org/10.1016/j.jaac.2011.07.006

55. Childs AW, Fite PJ, Moore TM, Lochman JE, Pardini DA (2014) Bidirectional associations between parenting behavior and child callous-unemotional traits: does parental depression moderate this link? J Abnorm Child Psychol 42(7):1141-1151. https://doi. org/10.1007/s10802-014-9856-y

56. Waller R, Gardner F, Viding E, Shaw DS, Dishion TJ, Wilson MN, Hyde LW (2014) Bidirectional associations between parental warmth, callous unemotional behavior, and behavior problems in high-risk preschoolers. J Abnorm Child Psychol 42(8):12751285. https://doi.org/10.1007/s10802-014-9871-z

57. Pardini DA, Fite PJ, Burke JD (2008) Bidirectional associations between parenting practices and conduct problems in boys from childhood to adolescence: the moderating effect of age and African-American ethnicity. J Abnorm Child Psychol 36(5):647-662. https://doi.org/10.1007/s10802-007-9162-z

58. Stepp SD, Whalen DJ, Scott LN, Zalewski M, Loeber R, Hipwell AE (2014) Reciprocal effects of parenting and borderline personality disorder symptoms in adolescent girls. Dev Psychopathol 26(2):361-378. https://doi.org/10.1017/S09545794130010 41

59. Besemer S, Loeber R, Hinshaw SP, Pardini DA (2016) Bidirectional associations between externalizing behavior problems and maladaptive parenting within parent-son dyads across childhood. J Abnorm Child Psychol. https://doi.org/10.1007/s1080 2-015-0124-6

60. Li JJ, Lee SS (2012) Interaction of dopamine transporter (DAT1) genotype and maltreatment for ADHD: a latent class analysis. $\mathbf{J}$ Child Psychol Psychiatry 53(9):997-1005. https://doi.org/10.11 11/j.1469-7610.2012.02563.x

61. Lehmann S, Havik OE, Havik T, Heiervang ER (2013) Mental disorders in foster children: a study of prevalence, comorbidity and risk factors. Child Adolesc Psychiatry Ment Health 7(1):39. https://doi.org/10.1186/1753-2000-7-39

62. Mandel DR, Lehman DR, Yuille JC (1995) Reasoning about the removal of a child from home: a comparison of police officers and social workers. J Appl Soc Psychol 25(10):906-921

63. Jones LP (2015) Was taking me out of the home necessary?' Perspectives of foster youth on the necessity for removal. Fam Soc 96(2):108-115

64. Bowlby J (1969) Attachment and loss: volume 1: attachment. The International Psycho-Analytical Library, and The Hogarth Press, London

65. Storebo OJ, Rasmussen PD, Simonsen E (2016) Association between insecure attachment and ADHD: environmental mediating factors. J Atten Disord 20(2):187-196. https://doi. org/10.1177/1087054713501079

66. Sonuga-Barke EJ, Rubia K (2008) Inattentive/overactive children with histories of profound institutional deprivation compared with standard ADHD cases: a brief report. Child Care Health Dev 34(5):596-602. https://doi.org/10.1111/j.1365-2214.2008.00863.x

67. Rutter M (1998) Developmental catch-up, and deficit, following adoption after severe global early privation. English and Romanian Adoptees (ERA) Study Team. J Child Psychol Psychiatry 39(4):465-476

68. Kennedy M, Kreppner J, Knights N, Kumsta R, Maughan B, Golm D, Rutter M, Schlotz W, Sonuga-Barke EJ (2016) Early severe institutional deprivation is associated with a persistent variant of adult attention-deficit/hyperactivity disorder: clinical presentation, developmental continuities and life circumstances in the English and Romanian Adoptees study. J Child Psychol Psychiatry 57(10):1113-1125. https://doi.org/10.1111/jcpp.12576

69. Bied A, Biederman J, Faraone S (2017) Parent-based diagnosis of ADHD is as accurate as a teacher-based diagnosis of ADHD. Postgrad Med 129(3):375-381. https://doi.org/10.1080/00325 481.2017.1288064 